\title{
Desidratação osmótica de pêssegos em função da temperatura e concentração do xarope de sacarose
}

\author{
Sílvia P. M. G ermer ${ }^{1}$, Marlene R. de Q ueiroz ${ }^{2}$, José M. Aguirre ${ }^{1}$, \\ Shirley A. G . Berbari ${ }^{1} \&$ Valéria D. Anjos ${ }^{3}$
}

\begin{abstract}
RESU MO
A desidratação osmótica pela qual passa a produção de fruta, é uma alternativa para o aproveitamento dos excedentes da persicultura. N este trabalho se avaliou a influência da temperatura e da concentração do xarope de sacarose na desidratação osmótica de pêssegos, e se investigaram variações de propriedades físicas, químicas e dos parâmetros da desidratação osmótica (perda de massa e de água; incorporação de sólidos). 0 delineamento central composto rotacional foi utilizado variando-se a temperatura (30 a 50 으) e a concentração ( 45 a $65^{\circ}$ Brix) da solução osmótica e se fixando a razão mássica xarope:fruta $4: 1$, tempo de processo $4 \mathrm{~h}$, e formato dos pedaços (metades). $\mathrm{Na}$ análise sensorial empregou-se 0 método de aceitação avaliando-se os atributos aparência, sabor, textura, cor e qualidade geral. Modelaram-se os resultados com o programa Statistica (v 6.0), através da M etodologia de Superfície de Resposta. O s seguintes modelos matemáticos resultaram significativos $(p<0,05)$ e preditivos: adimensionais dos teores de sólidos solúveis e do parâmetro $L^{*}$ de cor, parâmetros perda de água e perda de massa. A temperatura é o efeito preponderante. As condições de processo de 50 a $54,1{ }^{\circ} \mathrm{C}$ e 55 a $65^{\circ}$ Brix, proporcionaram maiores perdas de água e melhores desempenhos sensoriais.
\end{abstract}

Palavras-chave: Prunus persica (L.) Batsch, secagem, análise sensorial, metodologia de superfície de resposta

\section{O smotic dehydration of peaches as a function of temperature and concentration of sucrose syrup}

\begin{abstract}
The production of dried peach by osmotic dehydration is an alternative for using the excess of peach production. The influence of the temperature and concentration of the sucrose syrup in osmotic dehydration of peaches was evaluated. Variations in physical and chemical properties, and osmotic dehydration parameters (weight loss and water loss; solids incorporation) were investigated. An experimental central composite design was employed ranging the temperature (30 to $50 \stackrel{\circ}{ }$ ) and concentration ( 45 to $65^{\circ} \mathrm{Brix}$ ), keeping the syrup:fruit mass ratio $4: 1$, process time $4 \mathrm{~h}$, and format pieces (halves). The degree of acceptance was used in the sensory analysis, evaluating the following characteristics: appearance, taste, texture, colour and overall quality. The results were modelled using the Statistica program (v. 6.0) employing the Response Surface Methodology. The following mathematical models resulted significant $(p<0.05)$ and predictive: dimensionless soluble solids content and colour parameter $\mathrm{L}^{*}$, water loss and weight loss parameters. The temperature was the prevalent effect. The process conditions from 50 to $54.1{ }^{\circ} \mathrm{C}$ and from 55 to $65^{\circ}$ Brix presented more water loss and better sensory performances.
\end{abstract}

Key word: Prunus persica (L.) Batsch, drying, sensory analysis, response surface methodology

\footnotetext{
${ }^{1}$ Centro de Pesquisa e D esenvolvimento de Frutas e Hortaliças/Instituto de Tecnologia de Alimentos, CP 139, Av. Brasil 2880, CEP 13070-178, Campinas, SP. Fones: (19) 3743-1826; 1844; 1848. E- mail: sgermer@ital.sp.gov.br; maguirre@ital.sp.gov.br; sberbari@ital.sp.gov.br 2 FEAGRI/ U NICAMP, CP6011, CEP 13083-970, Campinas, SP. Fone: (19) 352-11073. E mail: marlene@ feagri.unicamp.br

${ }^{3}$ Grupo de Engenharia e Pós-colheita/ Instituto de Tecnologia de Alimentos, CP 139, Av. Brasil, 2880, CEP 13070-178, Campinas, SP. Fone: (19) 3743-1853. E mail: vanjos@ital.sp.gov.br
} 


\section{INTRODUÇÃO}

O Estado de São Paulo é o segundo produtor brasileiro de pêssegos e, embora produza cultivares de dupla finalidade (mesa e indústria), a industrialização é praticamente inexistente (Sato, 2001). A produção de fruta passa é uma das alternativas para o aproveitamento dos excedentes da persicultura paulista.

A aplicação da presecagem osmótica (PSO) como etapa inicial da desidratação de frutas, seguida por secagem com ar quente, é uma opção de processo que, no geral, resulta em produto de qualidade superior à dos obtidos por meios convencionais.

O processo de desidratação osmótica é aquele em que a retirada parcial da água de um alimento é obtida com o emprego de solução hipertônica com um ou mais solutos (Ponting et al., 1966).

A diferença de pressão osmótica estabelecida no sistema promove o fluxo de água do alimento para a solução constituindo-se, também, num fluxo contrário de solutos, em menor proporção, do xarope para o produto. Há, ainda, um terceiro fluxo, o de retirada de sólidos do alimento para a solução, de menor relevância quantitativa mas que pode causar importante perda de qualidade do produto (Raoult-Wack, 1994).

A aplicação da desidratação osmótica como processo preliminar à secagem convencional na produção de pêssegos passa foi reportada, mais recentemente, pelos seguintes autores: Mota (2005); Sahari et al. (2006); Germer et al. (2007; 2008). Vários aspectos foram abordados nesses estudos e, no cômputo geral, os resultados apresentaram excelentes desempenhos sensoriais e bons rendimentos de secagem, apontando para a viabilidade técnica do processo.

Germer et al. (2007), avaliaram o desempenho de cultivares de pêssegos produzidos comercialmente em São Paulo (Régis, Diamante, Aurora-1 e Douradão) para a produção de passas por processo combinado de PSO $\left(65^{\circ} \mathrm{Brix}, 45^{\circ} \mathrm{C}\right)$ e secagem com ar quente $\left(65^{\circ} \mathrm{C}\right)$ e concluíram que as cultivares Aurora-1 e Régis reúnem características de melhor aptidão.

Em trabalho subsequente, Germer et al. (2008) avaliaram a influência da temperatura e da concentração do xarope de sacarose nos parâmetros da desidratação osmótica e na variação das propriedades físicas e químicas de pêssegos cortados em fatias, assim como no desempenho sensorial do produto final. Os autores concluíram que a faixa ótima de trabalho seria de 50 a $54,1{ }^{\circ} \mathrm{C}$ e 45 a $65{ }^{\circ} \mathrm{Brix}$, resultando em perda de água da ordem de $50 \%$. Os tratamentos realizados nessas condições apresentaram, também, os melhores resultados, no que se refere à aceitação sensorial.

A desidratação osmótica tem sido amplamente estudada e a literatura apresenta, dentre outros produtos, diversos resultados para frutas e hortaliças. A transferência de massa e a qualidade do produto final da PSO, segundo os estudos, dependem de vários fatores, quais sejam: propriedades do tecido (Saurel et al., 1994; Raoult-Wack, 1994; Kowalska \& Lenart, 2001); grau de maturação, no caso das frutas (Chiralt \& Fito, 2003); temperatura de processo (Heng et al., 1990; Martins et al., 2008); tipo de soluto empregado (Heng et al., 1990); concentração do xarope (Heng et al., 1990; Park et al., 2002; Fernandes et al., 2006; Martins et al., 2008); formato e dimensões dos pedaços (Lerici et al., 1985); tempo de processo (Araújo, 2005) e razão mássica de xarope por produto (Lerici et al., 1985). Outros trabalhos relatam, também, a influência da agitação da solução (Azuara et al., 1996) e a aplicação de vácuo (Shi et al., 1995).

Objetivou-se com este trabalho foi verificar a influência da temperatura e da concentração do xarope de sacarose na variação de propriedades físicas e químicas do pêssego cortado em metades, bem como nos parâmetros da desidratação osmótica e no desempenho sensorial do produto final.

\section{Material e MÉTODOS}

O estudo foi conduzido com frutos da Cooperativa Agroindustrial Holambra, de Paranapanema, Estado de São Paulo, Brasil. A cultivar empregada foi a Aurora-1, de acordo com resultado de estudo anterior (Germer et al., 2007). Os pêssegos foram colhidos no estádio de maturação ótimo para a comercialização, quando da mudança da cor de fundo da casca, de verde para amarelo. Empregaram-se os frutos classificados na Categoria I (quanto aos defeitos) e classe/ calibre 2 (diâmetro de 45 a $51 \mathrm{~mm}$ ) segundo a norma do PBMH \& PIF (2008). Os pêssegos foram mantidos a $2{ }^{\circ} \mathrm{Ce} 80-90 \%$ de umidade relativa, e lotes dos frutos foram periodicamente retirados para os ensaios.

Empregou-se o delineamento experimental central composto rotacional, baseado na Metodologia de Superfície de Resposta (MSR), de acordo com o descrito por Barros Neto et al. (1995). Os fatores investigados foram temperatura $\left(30\right.$ a $\left.50{ }^{\circ} \mathrm{C}\right)$ e concentração do xarope ( 45 a $65^{\circ}$ Brix). O delineamento consistiu em 8 ensaios e 3 repetições no ponto central, de acordo com o apresentado na Tabela 1.

Tabela 1. N íveis codificados e decodificados das variáveis dos ensaios de presecagem osmótica de pêssegos em fatias

\begin{tabular}{ccccc}
\hline Ensaio & $\mathbf{T}$ & $\mathbf{C}$ & $\begin{array}{c}\text { Temperatura } \\
{ }^{\circ} \mathbf{C}\end{array}$ & $\begin{array}{c}\text { Concentração } \\
\text { ('Brix) }\end{array}$ \\
1 & -1 & -1 & 30,0 & 45,0 \\
2 & 1 & -1 & 50,0 & 45,0 \\
3 & -1 & 1 & 30,0 & 65,0 \\
4 & 1 & 1 & 50,0 & 65,0 \\
5 & 0 & 0 & 40,0 & 55,0 \\
6 & 0 & 0 & 40,0 & 55,0 \\
7 & 0 & 0 & 40,0 & 55,0 \\
8 & $-1,41$ & 0 & 25,9 & 55,0 \\
9 & 0 & 1,41 & 40,0 & 69,1 \\
10 & 1,41 & 0 & 54,1 & 55,0 \\
11 & 0 & $-1,41$ & 40,0 & 40,9 \\
\hline
\end{tabular}

\section{Ensaios experimentais}

Os frutos foram selecionados, lavados, descascados, descaroçados e cortados manualmente em metades. Realizouse branqueamento químico com solução de ácido cítrico (4\% p/p) e ácido ascórbico (1\% p/p), por 40 s. A secagem osmótica foi conduzida em 2 banhos idênticos com capacidade de $30 \mathrm{~L}$ providos de agitação $\left(10 \mathrm{~L} \mathrm{~min}^{-1}\right)$ (Immersion Circulation, Model 1266-02, EUA), nas condições estabelecidas pelo delineamento 
experimental. A razão de massa de xarope por massa de fruta foi de 4:1 (aproximadamente 18,4 kg de massa de xarope e 4,6 kg de massa de fruta), e o tempo de processo foi de $4 \mathrm{~h}$.

Ao final da operação de desidratação osmótica os pedaços foram retirados do banho, drenados, enxaguados e secados superficialmente com papel absorvente. Pesaram-se as matérias-primas e as frutas presecadas em balança mecânica (Mettler, P10N, Alemanha), reservando-se amostras para análise dos teores de umidade.

Os parâmetros perda de água (PA), perda de massa (PM) e incorporação de sólidos (IS) do processo de secagem osmótica, foram calculados a partir das seguintes relações:

$\mathrm{PA}=\frac{\left(\mathrm{U}_{\mathrm{f}} \mathrm{M}_{\mathrm{f}}-\mathrm{U}_{\mathrm{i}} \mathrm{M}_{\mathrm{i}}\right)}{\mathrm{M}_{\mathrm{i}}} \times 100\left(\mathrm{~g}\right.$ água $100 \mathrm{~g}^{-1}$ massa inicial $)$

$\mathrm{PM}=\frac{\left(\mathrm{M}_{\mathrm{f}}-\mathrm{M}_{\mathrm{i}}\right)}{\mathrm{M}_{\mathrm{i}}} \times 100\left(\mathrm{~g}\right.$ água $100 \mathrm{~g}^{-1}$ massa inicial $)$

$\mathrm{IS}=\frac{\mathrm{ST}_{\mathrm{f}} \mathrm{M}_{\mathrm{f}}-\mathrm{ST}_{\mathrm{i}} \mathrm{M}_{\mathrm{i}}}{\mathrm{M}_{\mathrm{i}}} \times 100\left(\mathrm{~g}\right.$ água $100 \mathrm{~g}^{-1}$ massa inicial $)$

em que:

$\mathrm{U}_{\mathrm{f}}$ - teor de umidade no final do processo, $\%$

$\mathrm{M}_{\mathrm{f}}$ - massa no final do processo, $\mathrm{g}$

$\mathrm{U}_{\mathrm{i}}$ - teor de umidade inicial, \%

$\mathrm{M}_{\mathrm{i}}$ - massa inicial, $\mathrm{g}$

$\mathrm{ST}_{\mathrm{f}}$ - teor de sólidos totais no final do processo, \%

$\mathrm{St}_{\mathrm{i}}$ - teor de sólidos iniciais, $\%$.

Em seguida à PSO, as metades foram enxaguadas e colocadas em bandejas para secagem complementar em secador de gabinete, com circulação de ar, na velocidade de $1,5 \mathrm{~m} \mathrm{~s}^{-1} \mathrm{e}$ temperatura de $65^{\circ} \mathrm{C}$. Os pesos das bandejas foram monitorados até que as amostras atingissem o teor de umidade na faixa de 20 a $22 \%$ (base úmida). O tempo de secagem foi de aproximadamente $5 \mathrm{~h}$. Os pêssegos passa foram embalados em sacos de polietileno de $0,15 \mathrm{~mm}$ de espessura e armazenados. Após um período aproximado de 15 dias, suficiente para o equilíbrio da umidade, realizaram-se os ensaios sensoriais.

\section{Análises físicas e químicas}

Realizaram-se, em cada ensaio, as seguintes análises com a matéria-prima e com a fruta, após a PSO (produto presecado): teor de umidade; teor de sólidos solúveis; acidez titulável; teores de açúcares redutores, não redutores e totais. Analisaram-se, na matéria-prima, cor $\left(\mathrm{L}^{*}, \mathrm{a}^{*}, \mathrm{~b}^{*}\right)$ e textura $\left(\mathrm{F}_{\max }\right)$ instrumentais e, também, a textura e a cor do produto final obtido após a secagem convencional (produto seco), na mesma época das análises sensoriais.

As análises dos teores de umidade foram realizadas em estufa com vácuo a $70^{\circ} \mathrm{C}$ até peso constante, segundo Carvalho et al. (1990). A acidez titulável (AT) foi determinada pelo método acidimétrico, segundo metodologia descrita por Carvalho et al. (1990). Os sólidos solúveis (SS) foram determinados por refratometria, empregando-se o refratômetro ótico de bancada Abbe (AO Abbe Refrectometer, Modelo 10450, EUA).

Os teores de açúcares totais (AÇT), redutores (AÇR) e não redutores (AÇNR) foram determinados pelo método de Munson e Walker, apresentado por Carvalho et al. (1990). As análises químicas foram realizadas em triplicata. A análise de textura, expressa em força máxima de corte $\left(\mathrm{F}_{\max }\right)$, foi realizada em texturômetro TAXT2i (Stable Micro Systems, Inglaterra) equipado com o probe "blade set with knife" (velocidade de pré-teste de $5 \mathrm{~mm} \mathrm{~s}^{-1}$, velocidade de teste de $1 \mathrm{~mm} \mathrm{~s}^{-1}$, força máxima de $25 \mathrm{~kg}$ ).

As análises de cor foram determinadas pelo Sistema CIElab no colorímetro Minolta CR300 (Minolta, Japão), por leitura direta na amostra com configuração d/0, iluminante D65, obtendo-se os valores de $\mathrm{L}^{*}($ luminosidade), a*(verde-vermelho) e $\mathrm{b}^{*}$ (amarelo-azul).

\section{Análise sensorial}

Para avaliar a aceitabilidade do produto final (produto seco) empregou-se uma equipe de 30 provadores, escolhida entre indivíduos consumidores de frutas secas. Utilizou-se uma escala hedônica com 9 pontos, sendo o valor 9 correspondente à avaliação "gostei muitíssimo" e 1 à avaliação "desgostei muitíssimo". Foram avaliados os atributos de aparência, sabor, textura, cor e qualidade geral. As amostras de pêssego passa foram apresentadas aos provadores em pratos de plástico branco. Os resultados foram avaliados através de análise de variância (Anova), Teste F e Teste de Tukey, empregando-se o programa SAS (SAS, 1993).

\section{Análises de regressão múltipla}

As médias dos parâmetros da desidratação osmótica e dos atributos sensoriais foram tratadas a partir de análises de regressão múltipla, para a obtenção de superfícies de resposta (SR), através do Programa Statistica versão 6.0 (Statsoft, Inc.).

Nos casos das propriedades físicas e químicas, para minimizar a variabilidade da matéria-prima fez-se o ajuste das superfícies aos valores adimensionais $\left(\mathrm{P}_{\mathrm{adm}}=\right.$ propriedade média do produto/ propriedade média da matéria-prima). Observaram-se as regressões estatisticamente significativas pela análise de variância (Anova), com base no teste F (Fisher), para o intervalo de $95 \%$ de confiança e do coeficiente de determinação da regressão $\left(\mathrm{R}^{2}\right)$, quando evidenciada a não significância da falta de ajuste.

Eliminaram-se os termos não significativos considerandose as regressões com $\mathrm{R}^{2}$ superior a $70 \%$ e $\mathrm{F}$ calculado $(\mathrm{Fc})$ superior ao F tabelado (Ftab), no nível de 5\% de significância ( $\mathrm{p}<0,05$ ). Considerou-se o modelo preditivo quando o $\mathrm{Fc} /$ Ftab foi maior ou igual 4, de acordo com Barros Neto et al. (1995).

\section{Resultados E Discuss Ão}

Observou-se nos ensaios realizados de PSO com pêssegos em metades e conforme esperado, um aumento do teor de sólidos solúveis (SS) (Tabela 2). O mesmo ocorreu com os teores de açúcares totais (AÇT) e açúcares não redutores 
Tabela 2. Val ores experimentais e adimensionais de propriedades químicas da matéria-prima e dos produtos para os respectivos ensaios de desidratação osmótica de pêssegos em metades

\begin{tabular}{|c|c|c|c|c|c|c|c|c|c|c|c|c|c|c|c|}
\hline \multirow[t]{2}{*}{ Ensaio } & \multicolumn{3}{|c|}{$\begin{array}{c}\text { SS } \\
\text { ( }{ }^{\circ} \text { Brix) }\end{array}$} & \multicolumn{3}{|c|}{$\begin{array}{c}\text { AT } \\
\left.\text { (g ac cítrico } 100 \mathrm{~g}^{-1}\right)\end{array}$} & \multicolumn{3}{|c|}{ 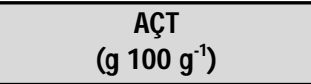 } & \multicolumn{3}{|c|}{$\begin{array}{c}\text { AÇR } \\
\left(\mathrm{g} 100 \mathrm{~g}^{-1}\right)\end{array}$} & \multicolumn{3}{|c|}{$\begin{array}{c}\text { AÇNR } \\
\left(\mathrm{g} 100 \mathrm{~g}^{-1}\right)\end{array}$} \\
\hline & $m p$ & ps & adm & $m p$ & ps & $\mathrm{adm}$ & mp & ps & $\mathrm{adm}$ & $\mathrm{mp}$ & ps & adm & $\mathrm{mp}$ & ps & $\mathrm{adm}$ \\
\hline 1 & 12,6 & 19,6 & 1,6 & 0,27 & 0,25 & 0,95 & 10,67 & 13,81 & 1,29 & 2,29 & 2,02 & 0,88 & 0,88 & 11,79 & 1,41 \\
\hline 2 & 12,2 & 26,8 & 2,2 & 0,28 & 0,19 & 0,68 & 10,91 & 14,27 & 1,31 & 1,71 & 1,87 & 1,09 & 1,09 & 12,40 & 1,35 \\
\hline 3 & 13,3 & 22,2 & 1,7 & 0,22 & 0,32 & 1,46 & 10,79 & 14,50 & 1,34 & 2,38 & 2,20 & 0,92 & 0,92 & 12,13 & 1,44 \\
\hline 4 & 13,1 & 30,4 & 2,3 & 0,32 & 0,23 & 0,74 & 10,86 & 16,56 & 1,52 & 1,89 & 2,34 & 1,24 & 1,24 & 13,85 & 1,54 \\
\hline 5 & 11,6 & 23,5 & 2,0 & 0,28 & 0,30 & 1,04 & 10,79 & 16,19 & 1,50 & 2,38 & 2,50 & 1,05 & 1,05 & 13,68 & 1,63 \\
\hline 6 & 13,6 & 24,1 & 1,8 & 0,35 & 0,26 & 0,74 & 9,41 & 13,75 & 1,46 & 2,31 & 2,59 & 1,12 & 1,12 & 11,16 & 1,57 \\
\hline 7 & 13,1 & 22,9 & 1,8 & 0,29 & 0,35 & 1,23 & 10,86 & 14,57 & 1,34 & 1,89 & 3,39 & 1,79 & 1,79 & 11,46 & 1,28 \\
\hline 8 & 13,3 & 19,4 & 1,5 & 0,31 & 0,28 & 0,90 & 10,67 & 12,97 & 1,22 & 2,29 & 1,36 & 0,60 & 0,60 & 11,61 & 1,38 \\
\hline 9 & 12,6 & 26,2 & 2,1 & 0,28 & 0,29 & 1,05 & 9,47 & 16,64 & 1,76 & 2,03 & 2,91 & 1,43 & 1,43 & 13,73 & 1,85 \\
\hline 10 & 14,6 & 30,1 & 2,1 & 0,26 & 0,25 & 0,97 & 9,47 & 19,56 & 2,07 & 2,03 & 2,56 & 1,26 & 1,26 & 17,00 & 2,29 \\
\hline 11 & 12,1 & 20,7 & 1,7 & 0,26 & 0,27 & 1,06 & 10,91 & 14,57 & 1,34 & 1,71 & 1,98 & 1,16 & 1,16 & 12,60 & 1,31 \\
\hline
\end{tabular}

$\mathrm{mp}=$ matéria prima; $\mathrm{ps}=$ produto presecado; $\mathrm{adm}=$ adimensional que indica a relação $\mathrm{ps} / \mathrm{mp}$

SS - sólidos solúveis; AT - acidez titulável; AÇT - açúcares totais; AÇR - açúcares redutores; AÇNR - açucares não redutores

(AÇNR). Os valores de AÇT estiveram menores que os de SS, provavelmente em razão da presença de outros solúveis na fruta, tais como pigmentos, ácidos e vitaminas.

Os adimensionais dos teores de açúcar não redutor se mantiveram ligeiramente maiores que os dos açúcares totais, com média de 1,56 contra 1,47, respectivamente (Tabela 2). Ocorreu, portanto, nesta condição da PSO, um incremento do teor de açúcares não redutores superior ao do teor de açúcares totais, levando à conclusão de que houve diminuição de açúcares redutores no processo. Esta hipótese está de acordo com os valores experimentais e adimensionais de AÇR que aumentaram relativamente menos, com média de 1,14 (Tabela 2).

Ressalta-se o fato de que a análise baseada em valor adimensional pode indicar o aumento ou a diminuição das propriedades físicas e químicas no processo. Por se tratar de operação de secagem, ou seja, de retirada de água, o aumento no valor dos parâmetros adimensionais quantitativos é previsto; no entanto, no caso de secagem osmótica as variações podem ser também de redução em razão das prováveis perdas de solúveis da fruta.

Quanto à acidez titulável, observa-se que os adimensionais estão próximos do valor $1 \mathrm{e}$, em alguns casos, ligeiramente menores (Tabela 2). A média de 0,98 dos valores sugere ter havido perda de ácidos orgânicos por parte da fruta no processo de PSO; o mesmo foi verificado por Argandoña (2005), na PSO de goiabas com solução de sacarose. Esses resultados estão de acordo com Raoult-Wack (1994), que apontam perdas de solúveis por parte dos alimentos na desidratação osmótica, tais como ácidos, pigmentos e vitaminas.

Com relação à variação da textura instrumental, observouse um aumento dos valores de força máxima, sendo que a média do adimensional desta propriedade foi de 3,12 (Tabela 3). O pêssego passa, portanto, obtido pelo processo combinado de $\mathrm{PSO} / \mathrm{SC}$ nas condições experimentais e faixas de teor de umidade praticados, exigiu uma força três vezes maior para o corte se comparado à fruta in natura.

Em relação à cor do pêssego no processo verifica-se, a partir dos parâmetros $\mathrm{a}^{*} \mathrm{e} \mathrm{b}^{*}$, que o componente amarelo, expresso pelo parâmetro $b^{*}$, é o de maior intensidade na coloração do pêssego Aurora-1 (Tabela 3). Este resultado está de acordo com Chitarra \& Carvalho (1985), que afirmam serem os carotenóides os principais pigmentos dos pêssegos, em especial o $\beta$ - caroteno (pró-vitamina A).

Observa-se, ainda, que no processo houve, um ligeiro decréscimo do parâmetro $b^{*}$ em alguns casos e, em outros, um pequeno aumento (Tabela 3). A média dos valores adimensionais de $b^{*}$ foi de 0,95 , indicando que, na prática houve, a conservação da coloração amarela. Esses resultados se assemelham aos obtidos por Heng et al. (1990) na PSO de mamão, e por Azoubel et al. (2008) na PSO de manga. No primeiro trabalho, os autores atribuem este fato à lipossolubilidade do

Tabela 3. Parâmetros da PSO e valores experimentais e adimensionais de propriedades físicas da matéria-prima e dos produtos secos para os respectivos ensaios da desidratação osmótica de pêssegos em metades

\begin{tabular}{|c|c|c|c|c|c|c|c|c|c|c|c|c|c|c|c|}
\hline \multirow{2}{*}{ Ensaio } & \multicolumn{3}{|c|}{$L^{*}$} & \multicolumn{3}{|c|}{$a^{*}$} & \multicolumn{3}{|c|}{ b* $^{*}$} & \multicolumn{3}{|c|}{$F \max (\mathrm{N})$} & PA & PM & IS \\
\hline & $\mathrm{mp}$ & s & adm & $\mathrm{mp}$ & $\mathbf{s}$ & adm & $\mathrm{mp}$ & $\mathbf{s}$ & adm & $\mathrm{mp}$ & $\mathbf{s}$ & adm & \multicolumn{3}{|c|}{ (g $100 \mathrm{~g}^{-1}$ massa inicial) } \\
\hline 1 & 68,3 & 64,5 & 0,9 & 5,8 & 7,0 & 1,2 & 41,0 & 37,2 & 0,9 & 23,5 & 66,9 & 2,8 & 22,7 & 19,4 & 3,2 \\
\hline 2 & 66,3 & 65,5 & 1,0 & 7,3 & 6,9 & 1,0 & 37,0 & 32,9 & 0,9 & 18,2 & 60,2 & 3,3 & 29,4 & 28,4 & 1,0 \\
\hline 3 & 71,3 & 59,2 & 0,8 & 2,9 & 8,9 & 3,1 & 35,2 & 38,6 & 1,1 & 21,1 & 53,7 & 2,5 & 32,5 & 27,7 & 4,9 \\
\hline 4 & 68,4 & 65,6 & 1,0 & 3,4 & 8,3 & 2,4 & 43,2 & 37,2 & 0,9 & 24,3 & 65,4 & 2,7 & 46,3 & 40,6 & 5,8 \\
\hline 5 & 69,0 & 62,0 & 0,9 & 4,0 & 10,5 & 2,6 & 41,8 & 35,5 & 0,8 & 19,9 & 65,3 & 3,3 & 34,6 & 28,1 & 6,5 \\
\hline 6 & 68,9 & 63,7 & 0,9 & 4,8 & 9,3 & 2,0 & 36,1 & 37,4 & 1,0 & 16,9 & 62,6 & 3,7 & 32,7 & 29,9 & 2,8 \\
\hline 7 & 69,4 & 62,5 & 0,9 & 5,3 & 9,3 & 1,8 & 44,0 & 43,6 & 1,0 & 17,6 & 56,6 & 3,2 & 32,3 & 28,6 & 3,7 \\
\hline 8 & 69,5 & 57,3 & 0,8 & 0,8 & 11,2 & 14,3 & 37,7 & 33,1 & 0,9 & 19,6 & 54,7 & 3,2 & 20,3 & 20,0 & 0,3 \\
\hline 9 & 70,7 & 60,1 & 0,9 & 2,5 & 9,9 & 4,0 & 37,8 & 31,3 & 0,8 & 17,5 & 64,2 & 2,8 & 36,5 & 33,5 & 3,1 \\
\hline 10 & 68,0 & 69,3 & 1,0 & 3,9 & 6,7 & 1,7 & 37,0 & 39,8 & 1,1 & 21,0 & 66,0 & 3,7 & 46,0 & 39,5 & 6,5 \\
\hline 11 & 68,4 & 63,5 & 0,9 & 2,5 & 8,4 & 3,3 & 34,5 & 35,2 & 1,0 & 20,9 & 74,0 & 3,1 & 24,2 & 22,0 & 2,2 \\
\hline
\end{tabular}

$\mathrm{mp}=$ matéria prima; $\mathrm{s}=$ produto $\mathrm{sec} 0 ; \mathrm{adm}=$ adimensional que indica a relação $\mathrm{s} / \mathrm{mp}$

L* - luminosidade; $a^{*}$ - verde-vermelho; b* - amarelo-azul; PA - perda de água; PM - perda de massa; IS - incorporação de sólidos 
Tabela 4. Médias dos atributos sensoriais dos produtos finais para os ensaios de secagem osmótica de pêssegos em metades

\begin{tabular}{|c|c|c|c|c|c|c|c|c|c|c|c|}
\hline \multirow{2}{*}{ Atributo } & \multicolumn{11}{|c|}{ Ensaio } \\
\hline & 1 & 2 & 3 & 4 & 5 & 6 & 7 & 8 & 9 & 10 & 11 \\
\hline Aparência & $6,77 a b$ & $6,86 a b$ & $6,32 a b$ & $6,77 a b$ & $5,95 b c$ & $6,59 a b$ & $6,05 a b c$ & $5,09 c$ & $6,41 \mathrm{abc}$ & $7,36 a$ & $6,73 a b$ \\
\hline Cor & $6,95 \mathrm{a}$ & $6,45 a b$ & $6,45 a b$ & 6,95 a & $6,18 a b c$ & $6,81 a b$ & $6,59 a b$ & $4,91 \mathrm{C}$ & $6,59 a b$ & 7,18 a & $6,45 a b$ \\
\hline Sabor & $6,73 a$ & 6,82 a & 6,91 a & $6,91 \mathrm{a}$ & $6,41 \mathrm{ab}$ & 6,86 a & $6,41 a b$ & $6,32 a b$ & 7,23 a & $7,45 a$ & 7,18 a \\
\hline Textura & $6,73 a b c$ & $7,45 a b$ & $6,09 \mathrm{c}$ & $6,86 a b c$ & $6,00 \mathrm{c}$ & $6,77 a b c$ & $6,18 b c$ & $6,55 b c$ & $7,45 a b$ & $7,86 \mathrm{a}$ & $7,00 a b c$ \\
\hline Qualidade geral & $7,18 \mathrm{a}$ & $6,91 \mathrm{a}$ & $6,64 a$ & $6,73 \mathrm{a}$ & $6,23 a b$ & $6,73 a$ & $6,5 a$ & $6,27 a b$ & $7,09 a$ & $6,91 \mathrm{a}$ & $7,00 \mathrm{a}$ \\
\hline
\end{tabular}

Médias seguidas das mesmas letras na mesma linha (comparação entre amostras) não diferem significativamente a nível de erro de $5 \%$ pela análise Anova

pigmento e, no segundo artigo, aponta-se para a menor exposição da fruta ao ar, o que causaria menor oxidação do pigmento.

Quanto ao parâmetro a* verifica-se que seu valor, embora menor que o anterior e mais variável na matéria-prima, triplicou em média no processo, indicando um aumento importante da coloração vermelha (Tabela 3 ). Este resultado está parcialmente de acordo com os apresentados por Riva et al. (2005) na PSO de abricó, quando foi observado um incremento importante do parâmetro $\mathrm{a}^{*}$ conjuntamente com a diminuição do parâmetro L*. Referidas alterações, segundo os mesmos autores, podem estar associadas às reações de escurecimento não enzimático e/ou enzimático no processo.

Ainda com relação à cor, notou-se ligeira diminuição do parâmetro L* em grande parte dos ensaios, resultando em um adimensional médio de 0,91 e indicando um leve escurecimento da fruta no processo (Tabela 3).

Com relação aos parâmetros da desidratação osmótica, constata-se que os valores de PM são menores que os valores de PA (Tabela 3). Portanto, nas condições estudadas ocorreram ganhos de sólidos solúveis por parte da fruta no processo, sendo que a média experimental da incorporação de sólidos (IS) foi de 3,6 g por $100 \mathrm{~g}$ de massa inicial. Este resultado é ligeiramente menor ao valor médio de $3,9 \mathrm{~g}$ por $100 \mathrm{~g}$ de massa inicial obtido por Germer et al. (2007) para pêssegos cortados em fatia.

Com relação ao desempenho sensorial dos produtos, algumas considerações podem ser feitas com base nas médias dos atributos sensoriais (Tabela 4). Em termos do atributo cor, a amostra do ensaio 10 obteve o melhor resultado, estatisticamente igual ao das amostras dos ensaios 1 e 4, com médias equivalentes a "gostei moderadamente; o pior desempenho do atributo cor foi da amostra 8, com média equivalente a "indiferente".

Para o atributo aparência (Tabela 4), o melhor desempenho foi obtido pela amostra do ensaio 10 , com média equivalente a "gostei moderadamente" e significativamente superior ao das outras amostras. As amostras dos ensaios 1, 2 e 4 estão na sequência das notas. $\mathrm{O}$ pior desempenho com relação a este atributo foi da amostra do ensaio 8, com média equivalente a "indiferente". As médias do atributo aparência são semelhantes às do atributo cor embora, no geral, com valores ligeiramente menores.

A amostra do ensaio 10 obteve o melhor desempenho quanto ao atributo "sabor" (Tabela 4), com média correspondente a "gostei muito" e estatisticamente igual às dos ensaios 9, 11, 3, 4, 6 e 2 e 1 . A amostra do ensaio 8 obteve a menor média para o atributo sabor, equivalente a "gostei ligeiramente".

Em relação à análise sensorial de textura o ensaio 10 resultou na amostra de melhor desempenho, estatisticamente superior às demais e com média equivalente a "gostei muito" (Tabela 4). O pior desempenho quanto ao atributo textura foi da amostra do ensaio 5, com média equivalente a "gostei ligeiramente".

Em relação ao atributo qualidade global, com exceção da amostra do tratamento 5, que apresentou o pior desempenho, as demais se equivalem estatisticamente e no nível de "gostei moderadamente" (Tabela 4).

Não foi possível estabelecer, para a textura, uma relação entre os resultados sensoriais (Tabela 4) e instrumentais (Tabela 3). Possivelmente, pequenas diferenças de umidade e de espessura das metades tenham influenciado as discrepâncias dos resultados.

Observa-se bastante coerência entre os resultados da cor sensorial (Tabela 4) e da cor instrumental (Tabela 3). O produto do ensaio 8 obteve a pior média para o atributo sensorial cor $\mathrm{e}$ também apresentou maior aumento do parâmetro L*, indicando escurecimento no processo. Além disto, o parâmetro a*, que expressa a cor vermelha apresenta, para esta amostra, um incremento considerável, o maior de todos. Por outro lado, a amostra do tratamento 10, que obteve a maior média para atributo sensorial cor, não apresentou alteração do parâmetro $L^{*}$, e pouca alteração no parâmetro $b^{*}$. Ainda que tenha havido um aumento do parâmetro a* para esta amostra, este foi relativamente menor se comparado com o da amostra 8. Houve, portanto, preferência pela amostra que não apresentou escurecimento, tendendo a um leve "clareamento".

Do exposto, verifica-se que as amostras 10 e 4 apresentaram, no geral, os melhores desempenhos sensoriais.

A média das notas obtidas no atributo qualidade geral (75\% da escala), se aproximam às obtidas por Mota (2005) com pêssegos em metades (variedade Biuti), e Buchweitz (2005) com kiwi em fatias, ambos em ensaios de desidratação osmótica com xarope de sacarose. Entretanto, comparando-se os resultados sensoriais de pêssegos em metade do atual artigo com aqueles obtidos por Germer et al. (2008) para o formato de fatias, observa-se que as médias dos atributos sensoriais das metades são ligeiramente inferiores. O atributo textura é uma exceção, com resultados um pouco melhores para as metades.

Os ajustes das SR dos adimensionais de SS e L* em função da temperatura e da concentração do xarope mostraram um bom nível de significância ( $\mathrm{p}<0,05)$, e os modelos obtidos, cujas curvas de contorno estão ilustradas na Figura 1, foram considerados preditivos pelos critérios adotados (Tabela 5). O 
Tabela 5. Resultados das análises de regressão múltipla das variações adimensionais do teor de sólidos solúveis, do L* de cor, e dos parâmetros PA e PM

\begin{tabular}{lcccrlcc}
\hline $\begin{array}{l}\text { Propriedade/ } \\
\text { parâmetro }\end{array}$ & $\mathbf{R}^{2}$ & $\mathbf{F}_{\mathbf{c}}$ & $\mathbf{F}_{\text {tab }}$ & $\mathbf{F}_{\mathbf{c}} / \mathbf{F}_{\text {tab }}$ & & Equação & Número \\
$\mathrm{SS}_{\text {adm }}$ & 0,74 & 25,63 & $5,12^{*}$ & 5,01 & $\mathrm{SS}_{\text {adm }}=1,87+0,27 \mathrm{~T}$ & $(4)$ \\
$\mathrm{L}^{*}$ adm & 0,84 & 21,29 & $4,46^{*}$ & 4,77 & $\mathrm{~L}^{*}$ adm $=0,92+0,06 \mathrm{~T}-0,032 \mathrm{C}$ & $(5)$ \\
$\mathrm{PA}$ & 0,93 & 21,38 & $4,53^{*}$ & 4,72 & $\mathrm{PA}=33,4+7,11 \mathrm{~T}+5,53 \mathrm{C}+1,24 \mathrm{C}^{2}-1,76 \mathrm{TC}$ & $(6)$ \\
$\mathrm{PM}$ & 0,97 & 117,37 & $4,46^{*}$ & 26,32 & $\mathrm{PM}=28,87+6,18 \mathrm{~T}+4,57 \mathrm{C}$ & $(7)$ \\
\hline
\end{tabular}

FC - F calculado; Ftab - Ftabelado; T- temperatura codificada; $C$ - concentração do xarope codificada

$* p<0,05 ; R^{2}$ - coeficiente de determinação

modelo do parâmetro PA, resultou, da mesma forma, significativo e preditivo, estando suas curvas de contorno apresentadas na Figura 2A. A análise da SR do parâmetro PM também resultou em modelo altamente significativo e preditivo (Tabela 5), estando suas curvas de contorno ilustradas na Figura 2B. Entretanto, não foram consideradas válidas, segundo os critérios adotados, as superfícies de resposta dos adimensionais das seguintes propriedades físicas e químicas: teores de açúcar total, redutor, e não redutor; acidez titulável, parâmetros a* e

$$
\text { A. }
$$

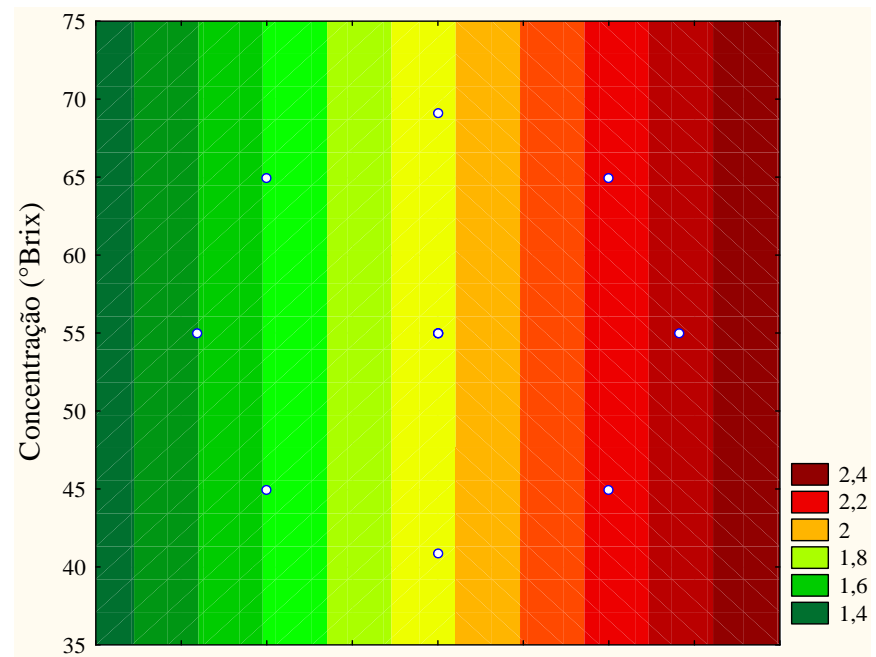

B.

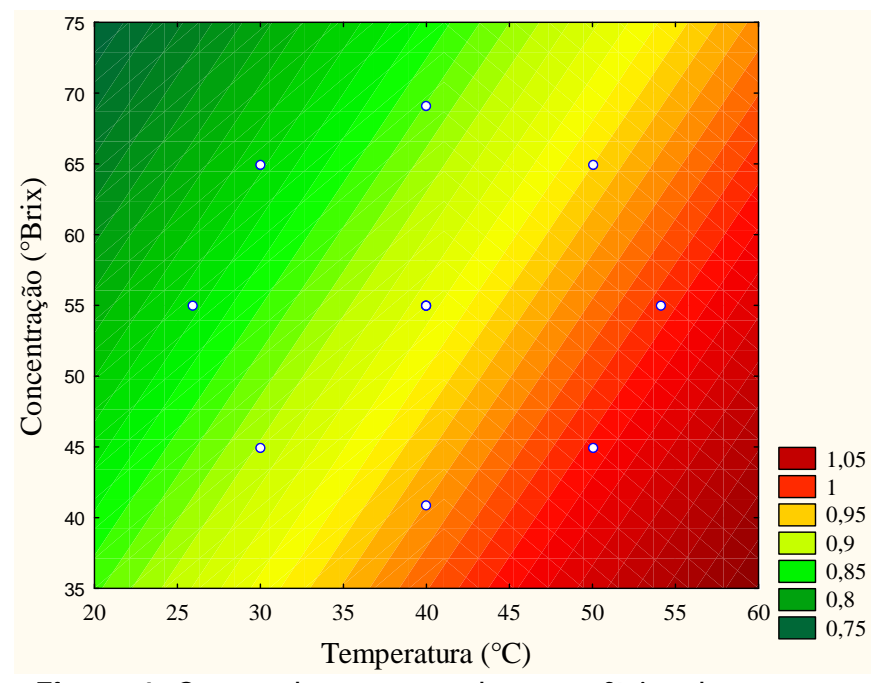

Figura 1. Curvas de contorno das superfícies de resposta para a variação adimensional do teor de sólidos solúveis (A) e do parâmetro L* (B) em função da temperatura de processo e concentração de xarope b* de cor; força máxima de corte. A análise da regressão múltipla da SR resultou em modelos estatisticamente não significativos para todos os atributos da análise sensorial no nível de 5\%, assim como no nível de $10 \%$ de significância.

Analisando-se o modelo referente à variação adimensional do teor de sólidos solúveis, Eq. 4 (Tabela 5), observa-se que a média é 1,87 , ou seja, na condição $\mathrm{T}=0$ e $\mathrm{C}=0$, a propriedade praticamente dobrou no processo. Nesta mesma equação se observa, também, que a temperatura é o único efeito

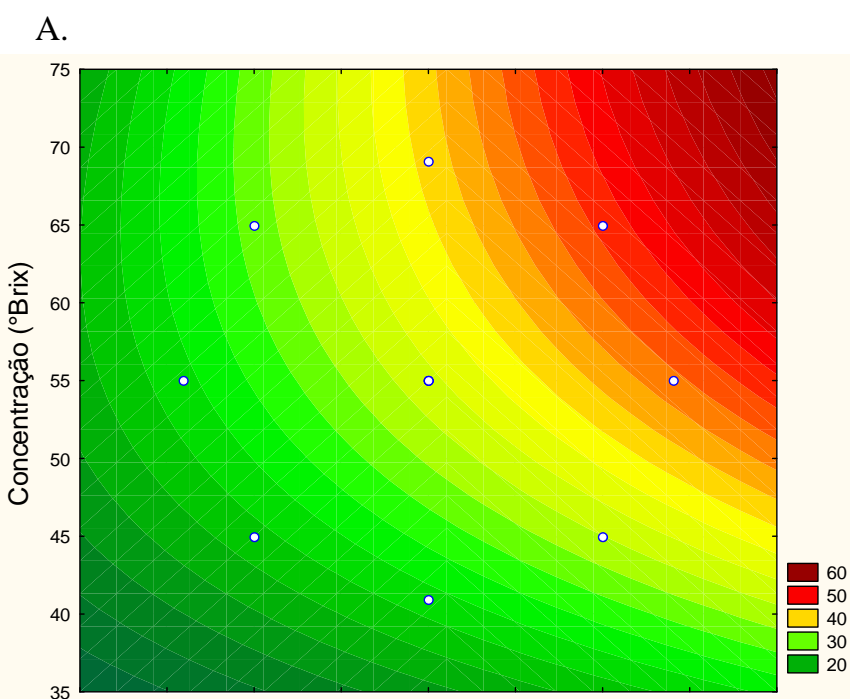

B.

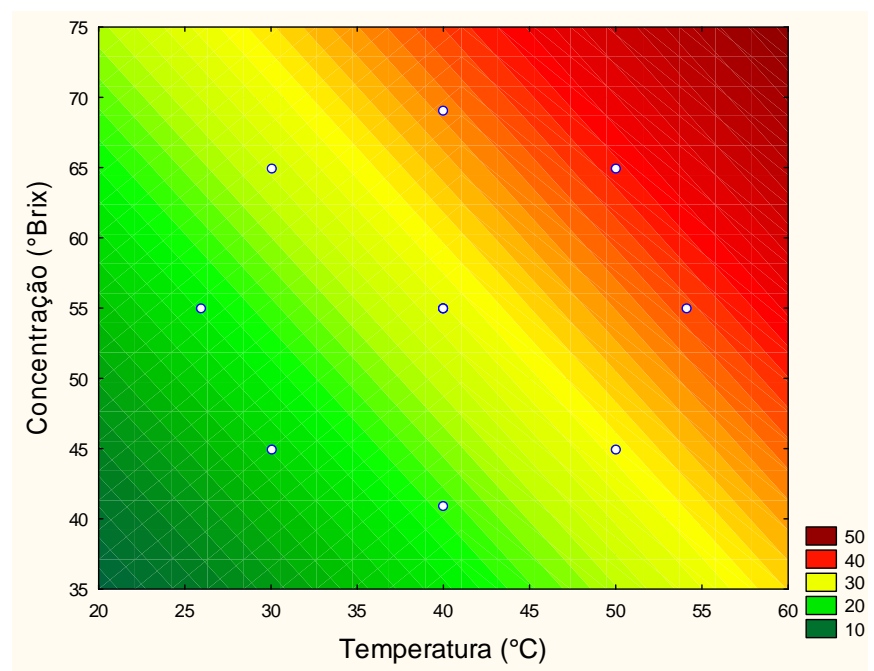

Figura 2. Curvas de contorno das superfícies de resposta para a variação do parâmetro perda de água $(A)$ e perda de massa (B) na PSO, em função da temperatura de processo e concentração de xarope 
significativo e positivo. $\mathrm{O}$ aumento da temperatura provoca, portanto, no intervalo estudado, elevação do teor de sólidos solúveis. Esses resultados estão em concordância com os de Pereira et al. (2006) em estudo sobre desidratação osmótica de mamão e goiaba. A razão para este fenômeno, segundo alguns autores (Saurel et al., 1994; Pereira et al., 2006), pode ser a alteração, com o incremento da temperatura, da permeabilidade da membrana celular, provocando um aumento crescente da absorção de sólidos. Dionello et al. (2009), por sua vez, não observaram, na desidratação osmótica de abacaxi, a mesma influência da temperatura; contudo, os distintos comportamentos podem ser atribuídos aos diferentes tipos de tecido vegetal.

Em relação à variação da cor no processo, conforme já apontado, apenas o adimensional do parâmetro L* apresentou, pelo modelo proposto, influência das variáveis investigadas (Tabela 5). Esta observação está em concordância com os resultados de Tan et al. (2001) em estudo da PSO de abacaxi, que concluíram ser a luminosidade o componente da cor que mais sofre influência das condições de processo.

No modelo de $\mathrm{L}^{*}{ }_{\text {adm }}$, conforme mostra a Eq. 5, a temperatura e a concentração têm influência através de seus termos lineares, sendo esses, respectivamente, positivo e negativo (Tabela 5). $\mathrm{O}$ termo de maior efeito é o da temperatura. $\mathrm{O}$ valor de $\mathrm{L}^{*}{ }_{\text {adm }}$ na região central do delineamento $\left(40^{\circ} \mathrm{C}\right.$ e $55^{\circ}$ Brix $)$, segundo o modelo, é de 0,92, indicando haver um leve escurecimento da fruta no processo (Tabela 5). Observa-se ainda, na Figura 1B, que em condições combinadas de temperatura maior e concentração menor, há tendência de aumento do $\mathrm{L}_{\mathrm{adm}}$, ou seja, tendência de "clareamento" do produto. Possivelmente este fenômeno seja provocado pela deposição e cristalização da sacarose na superfície da fruta, em decorrência, como já comentado, da maior absorção desta em temperaturas mais altas. Este resultado está em concordância com o obtido por Pereira et al. (2006) que observaram, na PSO de goiabas com solução de sacarose, aumento do $\mathrm{L}^{*}$ com a temperatura. $\mathrm{O}$ efeito negativo da concentração no modelo representado pela Eq. 5 pode estar relacionado à formação, em xaropes concentrados, de uma camada superficial de solutos na fruta, dificultando as trocas mássicas (Heng et al., 1990; Cunha et al., 2001; Pereira et al., 2006), e minimizando o ganho de solutos. A alta viscosidade dos xaropes concentrados e a dificuldade na agitação contribuem, também, para o fenômeno. Por outro lado, o aumento da concentração e a redução da temperatura resultam em escurecimento do produto, já que os valores de $\mathrm{L}_{\text {adm }}$ são menores que 1 nesta região. Este resultado está em concordância com Riva et al. (2005) que observaram a diminuição do parâmetro $L^{*}$ na secagem osmótica de abricó e apontaram, como causa provável, o escurecimento não enzimático.

Com relação ao modelo do parâmetro de secagem PA, expresso pela Eq. 6, o termo linear da temperatura é o de maior efeito, seguido do termo linear, da concentração (Tabela 5). Ambos os efeitos são positivos, contribuindo para o incremento da perda de água na PSO. No geral, o aumento da temperatura acelera e incrementa as trocas mássicas. Por outro lado, em tese, o aumento da concentração do xarope acentua o gradiente de pressão osmótica entre a fruta e a solução, estabelecendo uma força motriz maior para a transferência de massa; no entanto, no modelo expresso pela Eq. 6, o termo quadrático da concentração, embora de magnitude menor, se apresenta negativo. A explicação mais provável para este fato é a possível formação de regiões de estagnação provocada pela dificuldade de agitação nos xaropes mais concentrados devido às maiores viscosidades, dificultando as trocas mássicas. Por outro lado, o termo da interação temperatura/ concentração se apresenta positivo na Eq. 6, levando a crer que o aumento da temperatura minimiza o efeito negativo da concentração. Neste modelo há um efeito positivo da combinação das variáveis, contribuindo para o aumento da perda de água, ou seja, quanto maior a temperatura e a concentração, maior a perda de água. O modelo da Eq. 6 se assemelha ao obtido por Germer et al. (2008) para a variação da PA no estudo da PSO de pêssegos em fatia, realizado nas mesmas condições $\left(\mathrm{PA}=38,56+6,36 \mathrm{~T}+3,62 \mathrm{C}-1,99 \mathrm{C}^{2}-1,24 \mathrm{TC}\right)$. No entanto, algumas diferenças são observadas e, provavelmente, podem ser atribuídas às formas distintas dos pedaços. A média da Eq. 6 é menor se comparada com o valor obtido para fatias, indicando uma perda de água inferior para as metades na condição central do delineamento. O termo quadrático da concentração na Eq. 6 também é menor se comparado com o modelo de Germer et al. (2008). Possivelmente, para as metades o aumento da viscosidade dos xaropes mais concentrados prejudique menos a agitação. É provável que o formato arredondado das metades dificulte a adesão dos pedaços, mantendo-se espaços para circulação do xarope e minimizando, desta forma, o estabelecimento de zonas de estagnação. Além disto, no modelo das fatias, diferentemente do modelo da Eq. 6, o termo de interação temperatura e concentração é negativo. Sem dúvida, neste caso o aumento de temperatura não foi suficiente para melhorar a agitação e distribuição dos xaropes mais viscosos entre as fatias. Pode haver, ainda, um efeito deletério maior da temperatura no tecido das fatias, em função da menor espessura. Os resultados do modelo representado pela Eq. 6, também se assemelham aos obtidos por Mota (2005) na secagem osmótica de pêssegos cortados em metades da cultivar Biuti, a $65^{\circ} \mathrm{Brix}$, temperatura de $45^{\circ} \mathrm{C}$, por $5 \mathrm{~h}$, e com a relação massa de xarope:massa de fruta de 4:1. O percentual de redução de água obtido por Mota (2005) foi de aproximadamente $48 \%$, enquanto, segundo o modelo da Eq. 6, a perda de água foi de aproximadamente $42 \%$ para as mesmas condições. Há de se considerar, no entanto, que além dos diferentes tempos de processo outros aspectos experimentais podem ter influenciado, tais como tipo de agitação, dimensões das frutas e outros.

Quanto ao modelo da variação de PM, expresso pela Eq. 7, observa-se ser este bastante semelhante ao obtido para PA (Eq. 6) tendo, no entanto, coeficientes menores e não apresentando os termos quadráticos (Tabela 5). A temperatura é efeito preponderante e positivo. A concentração também apresenta efeito importante e positivo. Portanto, a variação da massa da fruta na PSO é maior quanto maiores a temperatura e a concentração.

Por fim, os modelos matemáticos obtidos podem ser empregados, também, no estabelecimento das melhores condições de processo. Tendo em vista um processo industrial, 
entende-se que as melhores condições sejam aquelas nas quais haja uma combinação das maiores taxas de retirada de água na PSO, com os melhores desempenhos sensoriais do produto final. Assim, ao se comparar a SR do parâmetro PA na Figura 2 com os resultados sensoriais da Tabela 4, observa-se que a região compreendida pelas faixas de temperatura de 50 a 54,1 ${ }^{\circ} \mathrm{C}$ e concentração do xarope de 55 a $65^{\circ}$ Brix combina os maiores valores de perda de água, na faixa de 41 a $47 \%$, e melhores desempenhos sensoriais.

\section{ConClusões}

1. As variáveis temperatura e concentração de xarope apresentaram, segundo modelos obtidos, forte influência nos parâmetros de secagem (perda de água e perda de massa), e menor influência nas variações físicas e químicas do pêssego em metades no processo de pré-secagem osmótica com xarope de sacarose. A variável temperatura foi o fator preponderante na maior parte dos modelos obtidos.

2. Quanto à variação da cor objetiva, apenas a luminosidade do produto $\left(\mathrm{L}^{*}\right)$ apresentou, segundo o modelo proposto, influência dos fatores investigados.

3. A região correspondente ao intervalo de temperatura de 50 a $54,1{ }^{\circ} \mathrm{C}$ e de concentração de 55 a $65^{\circ}$ Brix proporcionou a maior perda de água na pré-secagem de pêssegos em metade e os melhores resultados sensoriais dos produtos finais, podendo ser apontada como a região ótima de processo.

\section{Agradecimentos}

À Empresa Brasileira de Pesquisa Agropecuária (EMBRAPA) e ao Conselho Nacional de Desenvolvimento Científico e Tecnológico (CNPq), pelas bolsas concedidas. À empresa Sigmagropesquisa e à Cooperativa Agroindustrial Holambra, pela colaboração e apoio.

\section{LITERATURA CITADA}

Araújo, E. A. Estudo do processo de desidratação osmótica e secagem denectarina (Prunus persica). Campinas: UNICAMP, 2005. 113p. Tese Doutorado

Argandoña, E. J. S. Goiabas desidratadas osmoticamente e secas: Avaliação de um sistema osmótico semicontínuo, da secagem e da qualidade. Campinas: UNICAMP, 2005. 172p. Tese Doutorado

Azuara, E.; Garcia, H. S.; Beristain, C. I. Effect of the centrifugal force on osmotic dehydration of potatoes and apples. Food Research International, v.29, p.195-199, 1996.

Azoubel, P. M.; Oliveira, S. B.; Araujo, A J. B.; Silva, I. R. A.; Park, K.J. Influence of osmotic pretreatment on the total carotenoids content of dried mango. In: International Conference of Agricultural Engineering, Brazilian Congress of Agricultural Engineering, 37, Foz do Iguaçú. Anais...Foz do Iguaçu: SBEA/CIGR/ASABE. 2008. CD Rom.
Barros Neto, B.; Scarmino, I. S.; Bruns, R. E. Planejamento e otimização de experimentos. $2^{\mathrm{a}}$.ed. Campinas: UNICAMP, 1995. 299p.

Buchweitz, P. R. Avaliação da pré-secagem osmótica de kiwi (Actinidia deliciosa) complementada por processos convencionais. Campinas: UNICAMP, 2005. 224p. Tese Doutorado

Carvalho, C. R. L.; Mantovani, D. M. B.; Carvalho, P. R. N.; Moraes, R. M. Análises Químicas de Alimentos - Manual Técnico. Campinas: ITAL, 1990. 121p.

Chiralt, A.; Fito, P. Transport mechanisms in osmotic dehydration: The role of structure. Food Science and Technology International, v.9, p.179-186, 2003.

Chitarra, M. I. F.; Carvalho, V. D. Qualidade e industrialização de frutos temperados: Pêssegos, ameixas, figos. Informe Agropecuário, v.11, p.56-65, 1985.

Cunha, L. M.; Oliveira, F. A. R.; Aboim, A. P.; Frías, J. M.; Pinheiro-Torres, A. Stochastic approach to the modelling of water losses during osmotic dehydration and improved parameter estimation. International Journal of Food Science and Technology, v.36, p.253-262, 2001.

Dionello, R. G.; Berbert, P. A.; Molina, M. A. B.; Pereira, R. C.; Viana, A. P.; Carlesso, V. O. Desidratação osmótica de frutos de duas cultivares de abacaxi em xarope de açúcar invertido. Revista Brasileira de Engenharia Agrícola e Ambiental, v.13, p.596-605, 2009.

Fernandes, F.; Rodrigues, S.; Gaspareto, O. C. P.; Oliveira, E. L. Optimization of osmotic dehydration of papaya followed by air-drying. Food Research International, v.39, p.492-498, 2006.

Germer, S. P. M.; Queiroz, M. R. de; Aguirre, J. M.; Barbosa, W.; Berbari, S. A.; Sigrist, J. M. M.; Quast, E. Aptidão de cultivares de pêssego do Estado de São Paulo para a produção de passas por processo combinado de secagem osmótica e secagem com ar quente. Brazilian Journal of Food Technology, v.10, p.151-158, 2007.

Germer, S. P. M.; Queiroz, M. R. de; Aguirre, J. M.; Berbari, S. A. The influence of process variables on the osmotic drying and on sensory tests of sliced dehydrated peaches. In: International Conference of Agricultural Engineering, Brazilian Congress of Agricultural Engineering, 37, 2008, Foz do Iguaçú. Anais...Foz do Iguaçu: SBEA/CIGR/ASABE. 2008. CD Rom.

Heng, K.; Guilbert, S.; Cuq, J. L. Osmotic dehydration of papaya: influence of process variables on the product quality. Science des Aliments, v.10, p.831-848, 1990.

Kowalska, H.; Lenart, A. Mass exchange during osmotic pretreatment of vegetables. Journal of Food Engineering, v.49, n.2,3, p.137-140, 2001.

Lerici, C. R.; Pinnavaia, G.; Dalla Rosa, M.; Bartolucci, L. Osmotic dehydration of fruit: influence of osmotic agents on drying behavior and product quality. Journal of Food Science, v.50, p.1217-1226, 1985.

Martins, M. C. P.; Cunha, T. L.; Silva, M. R. Efeitos das condições da desidratação osmótica na qualidade de passas de caju-do-cerrado. Ciência e Tecnologia de Alimentos, v.28, p.158-165, 2008. 
Mota, R. V. Avaliação da qualidade físico-química e aceitabilidade de passas de pêssego submetidas à desidratação osmótica. Ciência e Tecnologia de Alimentos, v.25, n.1, p.789-794, 2005.

Park, K. J.; Bin, A.; Brod, F. P. R.; Park, T. H. K. B. Osmotic dehydration kinetics of pear D' Anjou (Pyrus communis L.). Journal of Food Engineering, v.52, n.3, p.293-298, 2002.

Pereira, L. M.; Ferrari, C. C.; Mastrantoni, D. S.; Rodrigues, A. C. C.; Hubinger, M. D. Kinetic aspects, texture, and colour evaluation of some tropical fruits during osmotic dehydration. Drying Technology, v.24, p.475-484, 2006.

Ponting, J. D.; Watters, G. G.; Forrey, R. R.; Jackson, R.; Stanley, W. L. Osmotic Dehydration of Fruits. Food Technology, v.20, p.125-128, 1966.

PBMH \& PIF - Programa Brasileiro para a modernização da horticultura \& Produção integrada. Normas de Classificação de Pêssego e Nectarina. São Paulo: CEAGESP, 2008.

Raoult-Wack, A. L. Recent advances in the osmotic dehydration of foods. Trends in Food Science \& Technology, v.5, n.8, p.255-260, 1994.
Riva, M.; Campolongo, S.; Leva, A. A.; Maestrelli, A.; Totteggiani, D. Structure-property relationships in osmoair-dehydrated apricot cubes. Food Research International, v.38, n.5, p.533-542, 2005.

Sahari, M. A.; Souti, M.; Emam-Jomeh, Z. Improving the dehydration of dried peach by osmotic method. Journal of Food Technology, v.4, n.3, p.189-193, 2006.

SAS. SAS/STAT User's guide. Version 6. Cary: SAS Institute, 1989. v.6, 1294p.

Sato, G. S. Produção de pêssegos de mesa e para indústria no Brasil. Informações Econômicas, v.31, n.6, p.61-63, 2001.

Saurel, R.; Raoult-Wack, A. L.; Rios, G.; Guilbert, S. Mass transfer phenomena during osmotic dehydration of apple. I. Fresh plant tissue. International Journal of Food Science and Technology, v.29, n.5, p.531-542, 1994.

Shi, X. Q.; Fito, P.; Chiralt, A. Influence of vacuum treatment on mass transfer during osmotic dehydration of fruits. Food Research International, v.28, n.5, p.445-454, 1995.

Tan, M.; Chua, K. J.; Mujumdar, A. S.; Chou, S. K. Effect of osmotic pre-treatment and infrared radiation on drying rate and color changes during drying of potato and pineapple. Drying Technology, v.19, n.9, p.2193-2207, 2001. 